\title{
Gender leadership as a social phenomenon: the experience of a narrative essay
}

\author{
Natalia Korostyleva \\ The Russian Presidential Academy of National Economy and Public Administration \\ Prospekt Vernadskogo, 84, 119571, Moscow \\ Russian Federation \\ e-mail: beek@rambler.ru \\ Ludmila Kovaleva \\ Voronezh State Technical University \\ 20 years of October str. 84, 394006, Voronezh \\ Russian Federation \\ e-mail: kafedra_rus@mail.ru
}

\begin{abstract}
Gender leadership is a complex and multifactorial process, inscribed into social norms and attitudes of the society. It is viewed as a social phenomenon based on an analysis of a narrative essay. It is a creative work, the distinguishing feature of which is the description of the author's personal attitude to a particular event, phenomenon or process. The article examines leadership on the basis of this analysis through social statuses and roles of men and women in Russian society. It shows typical gender-oriented leadership qualities, describes the image of women and men-leaders, and explores barriers that impede the advancement of women on the career ladder. The dependence of the essay's author on the gender picture of the world is shown, i.e., through the prism of gender-oriented stable stereotypes of thinking, value orientations, and behavior.
\end{abstract}

\section{Introduction}

Leadership is the process of interaction of a person who has leadership qualities with other people. These interactions are based on the position of power and subordination. And leadership as an authoritative attitude can (or cannot) be realized both by the leader him(her)self and his/her followers (Eagly 2007).

Leadership is determined by the nature of the society, its level of development, functions, mentality, culture, therefore leadership depends on social, economic, political and cultural factors, and from this point of view it can be viewed as a social phenomenon (Al-Kahtani 2018; or Strielkowski and Chigisheva 2018). In society, leadership is always associated with positions of distribution and consolidation of social statuses and roles. The cultural component of the leadership position depends on a system of values, morals, attitudes, and stereotypes.

Incorporating a gender approach into the process of forming and developing leadership allows us to consider female and masculine components, to analyze the factors influencing leadership of both men and women, to identify the pros and cons of this interaction, to understand women and men motivation and concerns in their desire to become leaders (see e.g. Bartol and Martin 1986; Jørstad 1996; Pulakos and O'Leary 2011; or Aidis and Schillo 2017). These and other researchers raised important problems related to models and styles of leadership of men and women, stereotypes of perception of men and women-leaders, issues about barriers to career development by women, the formation of their leadership qualities, etc. (see e.g. Eagly and Johnson 1990; Crawford and Unger 2004; Mishra and Singhania 2014; Strielkowski et al. 2016; Chvátalová 2016; Triana et al. 2017; or Bogdanović et al. 2018).

In this paper, we consider the understanding of leadership qualities and modern roles of men and women through a narrative essay, which is a creative work, the distinguishing feature of which is the description of the author's personal attitude to a particular event, phenomenon, or a process. It contains an evaluation category and the position of a thesis and an argument.

\section{Gender leadership through the prism of a narrative essay}

During the course "Gender Processes and Relationships in Management" at the Russian Academy of Science and Technology, the master students of "State and Municipal Management" and "Human Resources Management" of 2014-201, three forms of training, were given the task of writing an essay on "The Modern Image of Man and Woman: Leadership Qualities". 142 essays were analyzed, including 68 written by men, 74 
by women (from 2014 to 2018). The age of the master degree students is from 22 to 40 years. In general, the combine their studies with work, refer themselves to the middle class and live in different regions of Russia: central, southern, northern, Far Eastern cities-regional centers. More than half of them are married and have children.

The purpose of writing a narrative essay is to consider leadership through social status and the role of men and women in Russian society, to identify typical gender-oriented leadership qualities, the image of women and men-leaders, barriers that impede the advancement of women on the career ladder.

When it comes to gender leadership and social roles, one can see that transformation of gender roles is actively going on in Russian society. This was reflected in the essay of the undergraduates. They demonstrated a greater variety of women's roles over men's roles. The social roles of women are expanding, women are becoming more independent, especially in large cities, where there are more opportunities. Also, the range of leadership qualities of women increases with developing their status. A woman successfully realizes herself at work and at home. Typical reasoning of the students:

"A modern woman uses her times the way her life is full and diverse. She tries to do everything, be a loving mother and a caring wife and a successful professional at work."

(Angelica, female, 38 years old)

"A modern woman is a business lady with big and ambitious plans for the future. She is strict and graceful. She is successful at work, and her income is higher than that of a man. She is successful in negotiations. And very often she is a good leader".

(Ivan, male, 32 years old)

Most of the students note a wide range of roles for women. A man, in their opinion, is more difficult to integrate into the private sphere, less involved in family affairs, becomes more dependent on a woman.

"In my opinion, in modern society there is such a situation that men and women have changed their roles. Men lost their responsibility, they delegated making any decisions, regardless of their importance, to women".

(Tatyana, female, 24 years old)

"A modern man has ceased to be independent. All the important decisions that were always thought of to be on men's responsibility have passed to women. Even when it comes to small things: the choice of a restaurant, going to the theater, even flowers, men cannot choose without approval."

(Pavel, male, 23 years old)

Now the society has formed a social request for a family-oriented man. This was reflected in the reasoning of the students.

"The most relevant and new for us is a family-oriented man. Unlike the previous generation, he does not have a scope like "snatch a piece" from a large oil company. He is softer, but it does not mean that he is weaker. He just wants his human qualities to be realized in full, to have a beloved woman next to him. Although he no longer wants, like a new Russian, to just have her sitting at home, he understands that this is futile for the whole family. And for such a woman he is ready to fight. The main motive of all his actions is the family, not money. He devotes much time to self-education. He needs to know several languages, he must drive a car. And, of course, children are important to him. He wants his family not for one day."

(Sergey, male, 24 years old)

Despite this request, a man "present" in the family, performing all his family duties the same as his wife is a rarity. Existing objective social and cultural differences, traditions, norms, leave their imprint on the distribution of roles and responsibilities in the Russian family. According to Russian Public opinion Research Center (RPORC), in 60-75\% of families, parental responsibilities (dressing children, laying down to sleep, feeding, babysitting them, when sick, preparing lessons) are only on the mother's responsibility. Participation of a father in taking care of children in most cases is limited only to playing with them: $70 \%$ of men claim that they play with children. However, according to the answers of women, the share of such fathers is reduced to $50 \%$. In this case, $72 \%$ of the respondents believe that a man can cope with responsibilities for childcare and housekeeping as good as a woman. Respondents believe that if the father participates in the upbringing of children, the expected effects of such education will be respect for women (41\%), courage (32\%), responsibility (30\%) (WCIOM 2017). 


\section{Leadership and gender dimension}

When it comes to leadership as the gender dimension, our analysis of the essay showed that most often, both male and female authors note the following leadership qualities of women: activity, selfsufficiency, sociability, responsibility, success, decision-making skills, show strong character, and initiative. In the essay, traditional male leadership qualities are noted as: persistence, authority, activity, resoluteness, the ability to stand up for himself, defend his point of view, confidence, desire for superiority. This list of qualities shows the combinatorial leadership qualities of women and men. In fact, men and women leaders can behave relatively identically, manifesting certain qualities depending on the situation.

A similar conclusion is confirmed in the study of an American professor Cummings (2005). For five years, she had given the students the tasks to choose characteristic qualities for men-leaders and women from the list of leadership qualities. She noticed that participants in her seminars choose qualities that depended little on gender. She came to the conclusion that the modern image of the leader combined both male and female features and, depending on the situation, this or that quality would dominate (Cummings, 2005). Correctly using both male and female features of leadership and behavior, the leader will be able to interact with the subordinates in a qualitative and effective way and build harmonious relations with them.

The analysis of the men's essays showed a certain bias to female leaders. Negative connotations predominate in their attitude: "business person", "extremely strict", "ambitious", "stubborn and persistent", "careerist", "iron lady", or a "business lady". Among men, there are more traditional views on women's leadership, in fact, they demonstrate the patriarchy of views on the fact that leadership is a purely masculine affair, and a woman in the role of a leader is decried by them.

In some essays written by men, an instructive tone prevails, they seem to be trying to make "important prescriptions" for women how to behave with men. The position of secondary, patience, resignation against women is present in such essays.

"When a man is performing a role, do not expect perfection from him. Do not carp on trifles, do not interfere with the way he does it. If a man neglects the performance of male work, and as a result you face serious problems, do not complain. Just tell: "I have a problem." Clearly state the core of the problem and its consequences. Then ask: "What do you think, what to do about it?" Thus, you honor the man as the head of the family, shift the problem to the man's shoulders and help him to feel needed. If the man does not continue to solve the problem, have patience. Changes do not happen quickly".

(Pavel, male, 42 years old)

Let us note, in the women's essays the position of condemnation of both female and male leadership is absent. But the traditionalism of views on male and female leadership is still present in female essays, although this trend is not dominant.

"A modern man has a craving for leadership, and it was laid genetically. Therefore, he pays a lot of attention to his appearance, his body, because an attractive appearance in our time is of great importance in obtaining a higher position, especially if it concerns management, because the boss is the face of the company".

(Alina, female, 23 years old)

"I highlighted the qualities of a modern man for myself: a modern man should be a leader in at least one aspect of his life - in the family, at work, among friends. But at the same time, he must respect the authorities and be able not only to make decisions, but also to follow other leaders. A man in the 21st century should be strong, strong in everything, otherwise it's not a man, but just a gray, plain-looking person".

(Tatyana, female, 24 years old)

The explanation of the male leadership only by the presence of sexual dimorphism and the position of the obligation demonstrates the persistent gender stereotypes of young girls. In addition, the prevalent evaluation of women's leadership by the students is expressed in such typical arguments:

A woman leader is the one who is endowed not only with the privilege of choosing and implementing different roles, but also the right to be herself, to defend her interests, not to be afraid of anything.

Everything is possible for herself. She is a professional. She is a director. She is an astronaut. She is a minister. She is an Olympic champion".

(Valeria, female, 26 years old) 
“There are lots of ideas and projects in a modern woman-leader's head and she willingly shares and embodies them. A woman has ceased to be an ordinary housewife, no matter how busy she is, now she is engaged in science, sports, business, politics, has started running for president, exploring the space, and the list can be continued indefinitely".

(Maria, female, 31 years old)

"Factors such as equality, freedom of choice, the right to be themselves, to defend their views and interests have made women full and equal partners in the processes of the modern world. A striking example is women politicians in high positions of the state authorities, in the private sector of the economy or at multinational companies, which was previously regarded completely unnatural".

(George, male, 33 years old)

Much attention in the masters' essay is given to the image of a leader-woman and ta leader-man. Image shows the social status of a person, his authority and prestige. However, the students "superficially" evaluated the image of men and women, implying only external data: clothes, hair, manner of holding, grooming of the face and body.

When it comes to leadership and image (e.g. gender reading), in the essays of men, preference was given to the appearance of the female leader. They mostly describe the business style of women.

"In negotiations, the female boss does not accept flirting from men, and she sometimes earns several times more. It is not acceptable for her to appear in society with loose, lush hair, in a tight, bright dress decorated with bows and ruffles. A business suit or a black skirt to the level of her knee, with a white blouse. But there are exceptions".

(Eldiyar, male, 39 years old)

"I think that modesty of a woman leader should be in the first place when choosing clothes, and in this case, I do not mean the presence or absence of any jewelry."

(Herman, male, 23 years old)

"Women, career-oriented, actively use the services of beauty salons, monitor the condition of the ir hands and face, use the help of stylists. My wife, for example (runs the department in an international company) takes care of herself, she always has a manicure".

(Dmitry, male, 32 years old)

Men also note the need to lead a healthy lifestyle for women leaders.

"Given the increased emotional and physical loads in daily activities, a woman must give time to sports or activities associated with useful physical activity. Sports activities and other physical activities are a good prevention of depression, emotional and physical decay, as well as diseases."

(Oleg, male, 36 years old)

However, female authors notice that society prescribes to women a rigid image of a business woman. Elements of discrimination are present here.

"Despite some conditional equality, most women are stuck with discrimination in appearance; namely, they should look good in any situation, meet the ideals imposed by society. According to the accepted criteria, a successful modern woman should have an attractive appearance, a sporty body and try to maintain a beautiful image in any situation".

(T., unknown, 25 years old)

"In our society, first of all, women are judged by appearance, by the presence of family, husband and only then they can indicate that she has a good job or achievements in her career. Even if a woman is a Doctor of Science or a politician, most will appreciate her dress and hairstyle and may not notice the content of her speech."

(Svetlana, female, 39 years old)

Female essay authors do not bypass the male managers and describe their image in epithets: 'good body', 'athletic', 'manly', 'textured external data', 'stylish', 'smart', 'affable', 'smiling'.

Social, cultural and professional environment, of course, affect the image of women and men leaders, determine their main characteristics, but one should not forget about the professionalism and 
competence of leaders. By obtaining own image, leaders attract attention and respect from others, but in the students' essay, the image is under the 'pressing' of socially expected behavior of men and women. Women leaders are expected to have the skills to present themselves, to show a good business style in clothes, grooming and attractiveness, much less attention is paid to the professional aspects of women's activities. Men-leaders are also expected to show stylishness and good manners, the appearance of a man is also paid a lot of attention to. Some students describe the image of a metrosexual man in their essay.

"Male managers dress stylishly, they are sometimes very fixated on the exterior. There is a special direction in the image of a man - metrosexual. The one who loves to position himself, pays much attention to the way he looks. He is dressed according to current fashion”.

(Nadezhda, female, 24 years old)

Combining gender roles, family and work, is not an easy task for many of our respondents. In the essay, all the master students showed concern about the complexity of combining family and professional roles, especially for women with leadership qualities.

"If we consider a modern successful woman, then she must harmoniously combine two roles: to be a good mother, wife and move up the career ladder. It is quite problematic to combine two contradictory roles in a harmonious way".

(Lyubov, female, 28 years old)

"Life dictates its conditions. To adapt to them and succeed, a modern woman needs to have the appropriate qualities: business acumen, mobility, quick reaction, independence. And do not forget about the natural beginning, about all those qualities of a woman that make her a woman: sensitivity, charm, attractiveness, and housekeeping. To combine a woman's natural nature with modern rigid realities is an archetypal task".

(Svetlana, female, 37 years old)

Russian society exists in the cultural paradigm of the "mixed patriarchy", when the positions of the patriarchy and traditional values are combined with the position of egalitarianism, creating "mixed values" for both men and women. All the undergraduates write about the active position of women, the impossibility of realizing women only within the family. At the same time they set a "high bar" for women to be ideal mother and housewife, while understanding the complexity of this combination in the absence of a clear vision of the way out of the situation. According to the essay authors, a woman should have a large set of roles and to cope "excellent" with all of them. This creates a personal conflict, which is typical for many Russian women. The role conflict is perceived by a woman as a sense of a certain split between family and work: lack of time and energy, a sense of guilt before the family, lack of approval of her work by her husband and relatives.

Women in building a career are often hampered by internal attitudes that make it difficult to disclose their professional potential. They undermine themselves. The close environment of women often does not support them in their quest to pursue a career. Installations where a woman manifests herself more as a mother, a keeper of a home, compliant, dependent is supported by public opinion, especially by men, and is built into the social and role system of relationships between the sexes. In the essay of undergraduates, we find many such examples:

"Some time ago, the main concern of a woman was children and the duty to follow her husband. I think that the relevance of this will always take place. The word 'family' should remain in the first, priority place for a woman".

(Igor, male, 32 years old)

Strategies for getting out of the situation are seen by the master students in different ways. Most female essay authors rely on themselves in resolving the role conflict. They conduct time management and involve 'nanny' and 'grandmothers' institutes for solving their problems.

"I mostly count on myself in solving problems with family issues, much less on my husband. My five-year-old daughter has a nanny, she suits us, and we'll see what will happen in the future. But I will not resign from my work; I'm interested in self-improvement, in solving complex management tasks, in becoming more professional and successful".

(Maria, female, 33 years old) 
Many students are in favor of a flexible work schedule. According to some authors, psychological understanding of the importance of the female leader's activity, based on real results of work and their recognition by colleagues, as well as realizing their potential in areas where there is less fierce competition, a clear gender imbalance towards the female segregation (education, culture, medicine), helps to mitigate the conflict.

Although there are also those who understand the importance of solving the problem in the transformation of family policy and count on the state, but this trend does not prevail in the reasoning of the female essay authors. Russian citizens rely more on themselves in solving life situations than on the state.

\section{Conclusions and implications}

Gender leadership as an integral characteristic of success and hierarchy is a complex and integrated process, incorporated into the social-role system. In modern Russian society gender leadership is undergoing certain changes. Women's social roles are expanding and this leads to a transformation of the perception of women and men in the society. The image of a woman-leader is endowed with a positive content and there is a social request for a family-oriented man. But at the same time there are gender stereotypes, attitudes, barriers that prevent women from fully demonstrating and developing leadership qualities.

Through a narrative essay, we revealed a direct dependence of the image of women and male leaders on the gender picture of the world. Many male and female authors of the essay had largely 'double' attitudes toward gender leadership. On the one hand, they show the possibilities of modern women to realize themselves in the public sphere, to reveal their potential, accept a women as a manager and politician, public figure, athlete, cosmonaut, on the other hand, they explain the reasons for the imbalance in gender leadership in the natural 'superiority' of men and in the intrapersonal conflicts of women about the combination of professional and family roles.

The image of a woman and a man-leader is perceived by the authors of the essay rather traditionally through the external features of a leader: appearance, grooming, clothing, accessories. Leadership qualities of women and male leaders are recognized by undergraduates with a large proportion of androgyny. Leadership qualities, of both men and women, in their opinion, should manifest themselves depending on the situation, working conditions, and circumstances.

All in all, it appears that Russian society develops in the style of a 'mixed' patriarchy, where egalitarian attitudes are combined in numerous traditional ones (regarding the gender) in all spheres of life, and this explains the contradictory presentation of the material by the undergraduates on the topic of gender leadership.

\section{References}

Aidis R, Schillo RS (2017) Gender, leadership and venture capital: measuring women's leadership in VC firm portfolios. International Journal of Gender and Entrepreneurship 9(2):110-135. doi: 10.1108/IJGE-08-2016-0027

Al-Kahtani N S (2018) Perception of private telecom employees towards unfair HRM practices: an empirical investigation. Entrepreneurship and Sustainability Issues 5(4):957-966. doi: 10.9770/jesi.2018.5.4(18)

Bartol KM, Martin DC, Women and men in task groups. In: Ashmore R.D., Delboca F.K. (eds.) The social psychology of female-male relations, $1^{\text {st }}$ edn. (N.Y.; L.: Academic Press, 1986), pp. 259-310.

Bogdanović M, Vetráková M, Filip S (2018) Dark triad characteristics between economics \& business students in Croatia \& Slovakia: what can be expected from the future employees? Entrepreneurship and Sustainability Issues 5(4): 967-991. doi:10.9770/jesi.2018.5.4(19)

Crawford M, Unger R, Women and gender: A feminist psychology, $4^{\text {th }}$ edn. (McGraw-Hill, New York, 2004), $560 \mathrm{p}$.

Cummings A (2005) The 'Masculine' and 'Feminine' Sides of Leadership and Culture: Perception vs. Reality http://knowledge.wharton.upenn.edu/article/the-masculine-and-feminine-sides-of-leadership-andculture-perception-vs-reality/ Accessed 22 Aug 2018

Chvátalová I (2016) Social policy in the European Union. Czech Journal of Social Sciences, Business and Economics 5(1):37-41. doi: 10.24984/cjssbe.2016.5.1.4 
Eagly AH (2007) Female leadership advantage and disadvantage: Resolving the contradictions. Psychology of women quarterly 31(1):1-12. doi: 10.1111/j.1471-6402.2007.00326.x

Eagly AH, Johnson BT (1990) Gender and leadership style: A meta-analysis. Psychological Bulletin 108(2):233-256. doi: 10.1037/0033-2909.108.2.233

Jørstad J (1996) Narcissism and leadership: Some differences in male and female leaders. Leadership \& Organization Development Journal 17(6):17-23. doi: 10.1108/01437739610130528

Mishra US, Singhania D (2014) Contrasting the Levels of Poverty against the Burden of Poverty: An Indian Case. International Economics Letters 3(2):26-35.doi: 10.24984/iel.2014.3.2.1

Pulakos ED, O'Leary RS (2011) Why is performance management broken? Industrial and Organizational Psychology 4(2):146-164. doi: 10.1111/j.1754-9434.2011.01315.x

Strielkowski W, Chigisheva O (eds.) Leadership for the Future Sustainable Development of Business and Education, 1st edn. (Springer Proceedings in Business and Economics. Springer, Cham, 2018), 672 p., doi: $10.1007 / 978-3-319-74216-8$

Strielkowski W, Tumanyan Y, Kalyugina S (2016) Labour Market Inclusion of International Protection Applicants and Beneficiaries. Economics \& Sociology 9(2):293-302. doi: 10.14254/2071-789X.2016/9-2/20

Triana MDC, Richard OC, Yücel İ (2017) Status incongruence and supervisor gender as moderators of the transformational leadership to subordinate affective organizational commitment relationship. Personnel Psychology 70(2):429-467. doi: 10.1111/peps.12154

WCIOM (2017) Father today - more than a father? https://wciom.ru/index.php?id=236\&uid=692 Accessed 21 Aug 2018 